Artigo Original

\title{
Lazer, agressividade e violência: considerações sobre o comportamento das torcidas organizadas
}

\author{
Marcelo Fadori Soares Palhares \\ Gisele Maria Schwartz \\ Ana Paula Teruel \\ Danilo Roberto Pereira Santiago \\ Priscila Raquel Tedesco da Costa Trevisan
Laboratório de Estudos do Lazer (LEL), Departamento de Educação Física, IB- Universidade Estadual Paulista, Rio Claro, SP, Brasil

\begin{abstract}
Resumo: O futebol possui grande representatividade social em diferentes culturas. Porém, a paixão despertada nas torcidas pode gerar comportamentos agressivos e violentos, em um momento que deveria ser de diversão, caracterizando o lazer desviante, o qual ainda não está devidamente esclarecido. Esta pesquisa qualitativa teve como objetivo investigar, nos estudos acadêmicos, o comportamento agressivo das torcidas organizadas e seus desdobramentos no tempo destinado ao lazer. Para tanto, na pesquisa bibliográfica, buscou-se informações em obras de referência, compostas por livros e teses, além da consulta a diferentes bases de dados, com os descritores: lazer, torcidas organizadas, agressividade e violência. Os resultados indicam que, independente da gênese do comportamento agressivo, quando em presença de um grupo, ou dependendo do contexto sociohistórico, da composição das torcidas, da violência integrante da sociedade, da mídia, da má organização esportiva e da impunidade, estes fatores podem afetar mudança no comportamento individual, contribuindo para manifestações agressivas e violentas no âmbito futebolístico em campo e nas torcidas. Este tipo de manifestação pode favorecer a diminuição do público nos estádios, além de repercutir na delimitação das atividades vivenciadas no contexto do lazer. Estas condutas violentas podem, até mesmo, acarretar graves conseqüências nos âmbitos físico e/ou psíquico. Por fim, aponta-se a premência de políticas públicas específicas envolvendo o lazer e os megaeventos.
\end{abstract}

Palavras-chave: Lazer. Violência. Torcidas Organizadas.

\section{Leisure, aggressiveness and violence: considerations over the organized fans' behavior}

Abstract: Soccer has a great social representation in many cultures. But the passion developed in the fans can born aggressive and violent behaviors in a moment that should be for fun, characterizing the deviant leisure, theme that needs more investigation. This qualitative research has a main goal to investigate, in the academics studies, the aggressive behavior of the organized fans and their consequences in the leisure time. By a bibliographical research, information were found in reference material, composed by books and thesis, besides the use of databases, with the key-words: leisure, cheerleaders, aggressiveness and violence. The results show that, independently of the genesis of an aggressive behavior, other factors could interfere. When inside a group, or depending on the social-historical context, the profile of the fans, the violence of each society, the media, the poor organization of sport and impunity, these factors can affect individual behavior, contributing to aggressive and violent manifestations in soccer context, inside the field and inside the organizations of the fans. This kind of manifestation leads to a smaller audience at the stadiums, and even creating limitations in activities of leisure context. These violent conducts can bring serious physics and/or psychological consequences. After all, is pointed the necessity of specific public policies involving leisure and the international events.

Key-words: Leisure. Violence. Organized fans.

\section{Introdução}

A Revolução Industrial promoveu profunda transformação social e política na sociedade. As cidades começaram a se constituir ao redor das fábricas, formando grandes centros urbanos, enquanto, os trabalhadores do meio rural estabeleceram-se nos subúrbios das cidades (GOMES, 2008). Em decorrência disto, esses centros urbanos possuíam diversos imigrantes sem identificação com esse espaço e, tão pouco, com pessoas locais. Na tentativa de superação desses entraves, o futebol desponta como uma atividade na qual as pessoas podiam se reunir, gerando alguma identidade de grupo. Com isso, surgem os clubes de bairros, que fazem crescer o interesse social pelas cidades urbanas. Cresce também o sentimento de pertencimento a determinado grupo ou agremiação (TOLEDO, 1996). 
Ao longo dos anos, o futebol ganha importância no tempo destinado ao lazer da população em geral, como uma atividade que proporciona prazer e inúmeras emoções. Logo, acaba sendo muito presente no tempo destinado ao lazer, tanto em relação à sua prática, quanto em relação à assistência, chegando a ser um fenômeno social muito representativo (ESCHER; REIS, 2006).

Todavia, a paixão despertada pelo futebol não se apóia apenas em elementos hedonísticos, podendo, inclusive, gerar comportamentos agressivos e violentos em um momento que deveria ser de diversão. Os confrontos físicos entre as torcidas, prática recorrente em muitos países, poderiam caracterizar 0 que se convencionou chamar de lazer desviante (STEBBINS, 1997; ROJEK, 1999a; WILLIAMS; WALKER, 2006). Este é caracterizado por condutas que ferem os princípios e normas morais de uma sociedade, práticas geralmente ligadas à criminalidade. Assim, por intermédio da vivência exacerbada do prazer, procura-se justificar condutas anti-sociais (WILLIAMS; WALKER, 2006).

Conquanto haja grande interesse em se focalizar o futebol como prática desportiva, pouco ainda se conhece sobre os elementos subjetivos envolvidos nesta atividade. As questões referentes à vivência de prazer e a adoção de condutas violentas são ainda bem pouco explorados e merecem atenção acadêmica, o que instigou o olhar deste estudo.

Dentro desta premissa, o objetivo desta presente pesquisa foi investigar, nos estudos acadêmicos, o comportamento agressivo das torcidas organizadas e seus desdobramentos no tempo destinado ao lazer. Para atender a tal objetivo, deve-se, inicialmente, diferenciar agressividade e violência.

A agressividade seria a capacidade ou 0 potencial que determinado individuo possui para realizar uma ação violenta. Já a violência é uma forma do comportamento agressivo, na qual a pessoa possui intenção em lesar outrem de maneira grave (MACHADO, 1997). Cabe salientar desde já, que a violência é um fenômeno amplo e não está restrita aos esportes. Para se compreender esse aspecto subjetivo, deve-se considerar o contexto social de uma forma mais ampla, pois a violência pode possuir diversas causas (ESCHER; REIS, 2006). Este artigo discutirá, mais especificamente, a violência no futebol, sua relação com o comportamento das torcidas organizadas (T.O.), assim como, seus impactos no tempo destinado ao lazer da população.

Em relação à compreensão sobre a representatividade social do futebol, por exemplo, no que tange à escolha de um time, não raro, esta já ocorre logo ao nascimento, por pressão familiar (REIS, 2006). Outro exemplo seria a quantidade de pessoas que uma única partida chega a movimentar, assim como, suas ressonâncias nos dias posteriores às partidas. A atenção de muitas pessoas e da mídia, não raro, continua focada em determinada partida de futebol que ocorreu há dois ou três dias atrás, gerando repercussões interessantes e, muitas vezes, inexploradas pelos estudiosos.

Para entender um pouco mais do significado do futebol para o brasileiro, Daólio (2005) o apresenta, assim como o carnaval, como manifestações populares, que seriam capazes de expressar a sociedade brasileira. Já Da Matta (1982) categoriza o futebol como uma expressão de representações e dramatizações da sociedade brasileira, ou seja, a partir do futebol a sociedade brasileira é descoberta e expressa suas características.

O aumento da afinidade da população pelo futebol fez com que este se profissionalizasse, fato fundamental na expansão do futebol de forma global. Tal fato contribuiu também para sua ampliação no território brasileiro (REIS, 2006). Segundo Toledo (1996) o futebol já era considerado um esporte de massa em 1930, todavia, cabe ressaltar alguns aspectos que contribuíram posteriormente na sua expansão e disseminação. Uma delas foi referente às transmissões por rádio na década de 30 , pelas quais se iniciou a expansão em relação ao esporte bretão.

$\mathrm{Na}$ década de 50 , por meio da televisão, as partidas ganharam um atrativo a mais, a imagem. Agora, era possível visualizar aquilo que o rádio não permitia, atraindo, assim, mais adeptos. Estes fatos foram somados aos dois primeiros títulos mundiais conquistados pelo Brasil no final da década de 50 e início de 60 , além da utilização da imagem da seleção campeã mundial em 1970 como propagandas política, por parte do governo militar. Estes fatos também contribuíram neste processo de expansão (REIS, 2006).

Por fim, o aumento do número de campeonatos e estádios contribuiu para a afirmação do futebol como mania nacional. Estes elementos, por sua vez, retiraram a perspectiva mais local do futebol, expandindo-o em âmbito nacional. O primeiro Campeonato Brasileiro realizado em 1971 comprova tal expansão, pois 
este oportunizou confrontos até então inéditos no futebol nacional.

Devido à expansão e representatividade social do futebol, por fim, este passa a ser alvo de investimentos em dinheiro e propaganda. Em meio ao processo de expansão e consolidação do futebol em âmbito nacional, diversas pessoas passam a se interessar em praticá-lo, assim como, em acompanhá-lo (TOLEDO, 1996). Surgem então, movimentos e grupamentos de pessoas que possuíam afinidade e gostos em comum, que ultrapassavam os times, surgindo, assim, as torcidas.

\section{Torcidas Organizadas}

Para a compreensão do surgimento das torcidas, Toledo (1996) explicita inicialmente o processo histórico de desenvolvimento das mesmas, salientando como ponto principal, a diferenciação no público de uma partida de futebol. Tal diferenciação é decorrente do surgimento das torcidas uniformizadas e, posteriormente, das organizadas.

Sendo assim, surge uma ruptura entre o público em uma partida de futebol, em que se nota o torcedor comum e o organizado. O torcedor comum é aquele que acompanha os jogos, independentemente da freqüência, e local do estádio, sendo que este torcedor não está associado a nenhum tipo de grupo. Já os torcedores organizados são aqueles vinculados a determinado grupo e corroboram suas regras (PIMENTA, 1997).

Como componentes de um contexto social maior, as torcidas organizadas, assim como qualquer outra organização, estão sujeitas a adequação aos parâmetros sociais. Logo, devese sempre levar em consideração o contexto social mais amplo. Desta forma, pode-se melhor compreender alguns fatos que serão aqui expostos em relação às torcidas. Para Reis (2005) estes parâmetros sociais são definidos pelo capital.

As primeiras torcidas organizadas eram grupamentos de pessoas que visavam apoiar seus clubes, com a utilização de instrumentos musicais, de uma forma alegre e com a utilização de uniformes. Este conjunto de pessoas era denominado de "charanga", ou seja, eram torcedores equipados com instrumentos musicais e uniformes. Estas charangas possuíam um chefe de torcida, o torcedor-símbolo. A Torcida Uniformizada do São Paulo, criada em 1940 e a Charanga do Flamengo, criada em 1942 foram apontados como os primeiros movimentos enquanto uma torcida organizada, nos estudos consultados (TOLEDO, 1996; PIMENTA, 1997; MURAD, 2007).

Considerando a sociedade atual, as torcidas tiveram de aderir ao modelo capitalista de existência. Desta forma, as torcidas organizadas, nos moldes contemporâneos, mais se assemelham a empresas. Possuem organização burocrática, contendo: Conselho Deliberativo e Fiscal, Diretoria Executiva, Conselho Vitalício, estatuto, quadro de associados, mensalidades e eleições (PIMENTA, 1997).

Este esquema de organização demonstra uma espécie de evolução organizacional nas torcidas, uma vez que estas apresentam algo além da simples uniformização dos componentes. O termo "torcida uniformizada" é anterior ao termo "torcida organizada", porém ambas podem coexistir (TOLEDO, 1996). Este fato demonstra a possível evolução ou, simplesmente, uma nova forma de organização dentro destas instituições. Tal forma perpassa ainda a oferta de projetos sociais e serviços aos seus associados e à comunidade.

Ao se procurar efetivamente compreender o que deu início ao surgimento da mobilização de pessoas em torno das torcidas, Mário Filho (1964) relata, em seu estudo, que o uso de fitas específicas no chapéu por parte de alguns torcedores, mais especificamente os sócios, é que foi um marco importante. Estas fitas eram trazidas da Europa, a fim de marcarem um grupo característico de espectadores. Tal símbolo gerava grande expectativa em relação a sua chegada, pois, sem a fita pendurada no chapéu, o individuo não pertencia ao grupo. Sendo assim, estes torcedores, que não possuíam a identificação do grupo, sentiam-se excluídos e até mesmo humilhados.

Todavia, Pimenta (1997) explicita que episódios como este não poderiam marcar o início das torcidas organizadas, pois somente a vestimenta, o pertencimento e identificação ao grupo, elementos presentes no caso supracitado, não são suficientes para caracterizar uma torcida organizada. A caracterização de uma torcida organizada perpassa diversos elementos, os quais serão abordados adiante.

As Torcidas Organizadas, assim como se entende hoje contendo estatuto e estrutura organizacional interna, começaram a existir no final da década de 60 e início de 70. O Grêmio Gaviões da Fiel, com fundação em 1969 é considerada a primeira torcida organizada (TOLEDO, 1996; PIMENTA, 1997). Ambos os trabalhos relatam a indignação da torcida com a falta de títulos que o clube enfrentava, além do desejo de mudança do presidente do clube. Este 
fato revela o objetivo principal de surgimento das torcidas: exercer pressão política em relação aos clubes.

Toledo (1996) aborda a questão expondo que os torcedores organizados começaram a buscar direitos, que Ihes foram negados, enquanto "simples" torcedores comuns. Cobravam melhores resultados e mudanças na estrutura dos clubes, utilizando, posteriormente, inclusive comportamento agressivo para estas reivindicações. Segundo Pimenta (1997) as torcidas necessitam de episódios de autoafirmação, do uso da violência como fator de afirmação e das transgressões. A Mancha Verde é utilizada como exemplo pelo autor, pois surge da união de diversas pequenas torcidas cansadas de sofrerem agressões das torcidas rivais. Tais elementos de revolta ficam evidentes, inclusive, na escolha do mascote da torcida, representado por um personagem com imagem ligada à criminalidade.

Com o passar dos anos, as torcidas vão se firmando, inclusive por meio da violência, e passam a ganhar notoriedade na mídia e na sociedade, principalmente nos anos 90. Nesta década, o quadro de associados cresce de maneira significativa e ocorrem diversos episódios violentos, culminando no episódio da luta campal ocorrida no Pacaembu, no ano de 1995, conforme relatou (TOLEDO, 1996; PIMENTA, 1997).

Após este fato, algumas das torcidas organizadas envolvidas em episódios violentos foram banidas. $O$ fenômeno das torcidas ganha atenção dos meios de comunicação e é evidenciada a ressonância destes problemas relacionados à violência dentro do campo de futebol. Assim, agora afetando diretamente 0 jogo, passam a ser discutidas possíveis soluções para o problema.

Mediante esta pequena incursão histórica e a exposição dos problemas relativos à violência constante no âmbito do futebol, seja em campo ou nas torcidas, surgem outras inquietações. $O$ comportamento das torcidas organizadas, vivenciado no contexto do lazer, fenômeno cultural ampliado a partir da organização social do trabalho, pode ser considerado dentro das premissas do que se convencionou chamar de lazer desviante (STEBBINS, 1997; ROJEK, 1999a; WILLIAMS; WALKER, 2006)? Quais as ressonâncias deste fenômeno no tempo destinado ao lazer da população em geral? Estas e outras inquietações advindas da reflexão serão tratadas a seguir.

\section{Torcidas Organizadas, Hooligans e Lazer Desviante}

O lazer desviante é caracterizado por condutas transgressoras à lei e aos princípios morais de uma sociedade, justificando tal comportamento pela vivência intensa ou exacerbada do lazer (STEBBINS, 1997; ROJEK, 1999a; WILLIAMS; WALKER, 2006). Dentre as práticas realizadas no âmbito do lazer desviante vivenciadas especificamente pelos torcedores de futebol, destacam-se: depredação de transporte coletivo, trens, metrôs, patrimônio privado e público, arrastões, brigas, saques e roubos. A partir deste cenário destrutivo, começaram a existir diversas campanhas de conscientização para os torcedores, como a que foi realizada pelo metrô de São Paulo (PIMENTA, 1997). Nesta ação, foi criado um torcedor símbolo, Sampaio, o qual utilizava a linguagem do futebol a fim de transmitir valores em relação à necessidade de se seguir as regras, tanto esportivas, quanto sociais. Sendo assim, a criação deste torcedor símbolo, visava a conservação do espaço do metrô.

Ao citar estes tipos de comportamentos fora do Brasil, pode-se encontrar as ações dos hooligans. Inicialmente, o termo hooligan pode designar, tanto um comportamento ligado a uma família que apresenta conduta anti-social, quanto a um grupamento específico de torcedores. Dunning (1992) investigou o hooliganismo e, a partir de seus estudos, se pode estabelecer importantes diferenças entre este movimento e o movimento das torcidas organizadas.

Pimenta (1997, p. 66) caracteriza uma torcida organizada (T.O.) por tais elementos: "[...] vestimenta, virilidade, cânticos de guerra, transgressões à regra, coreografias, sentimento de pertencimento ao grupo.". O mesmo autor ainda destaca as relações verticalizadas, a coesão grupal e o estilo de vida (PIMENTA, 1997), como elementos que permeiam a caracterização das torcidas organizadas.

Para a identificação dos hooligans, entretanto, algumas características os diferem das T.O.. A primeira característica que difere os hooligans é que estes possuem afinidade com movimentos políticos de extrema direita, com ideais xenofóbicos e, constantemente, discutem questões políticas, defendendo posições nacionalistas.

Os hooligans estão camuflados, ou seja, não possuem vestimenta diferenciada dos demais torcedores. Desta forma, estão diretamente vinculados ao clube, diferentemente das torcidas organizadas, em que os componentes vestem a camisa da torcida e não a do clube. As táticas 
militares avançadas, utilizadas para os confrontos com o intuito de driblar os órgãos públicos de segurança, também os diferem das T.O. Em alguns confrontos entre hooligans também já se notou a utilização de armas de fogo, fenômeno não tão constante no Brasil, mas que, ultimamente, é uma prática crescente (TOLEDO, 1996; PIMENTA, 1997; REIS, 2006).

Certamente, ambos os fenômenos convergem na utilização de violência como estratégia de auto-afirmação, assim como, na existência de pequenos grupos fanáticos, enfrentamento com a polícia e alto grau de rivalidade. Tais elementos, combinados a outros como: má organização esportiva, declarações vinculadas na mídia e questões físicas do estádio, são também capazes de provocar manifestações agressivas e violentas por parte dos torcedores.

Efetivamente, as similaridades entre torcidas organizadas e hooligans são maiores do que as diferenças, contudo deve-se compreender 0 contexto sociohistórico do desenvolvimento de cada fenômeno. Assim, ambos são fenômenos diferentes e necessitam de olhar especial, tendo em vista as peculiaridades de realidades $e$ contextos.

Independentemente de tais diferenças, uma das similaridades mais frequentes entre as T.O. e hooliganismo é o envolvimento em brigas entre facções rivais ou não e, até mesmo, com os policiais, além do prazer decorrente de tal prática, as quais são frequentes. É justamente este prazer em burlar as regras e ultrapassar os limites éticos que caracteriza o lazer desviante, um dos desafios a serem ainda elucidados dentro da complexidade dos aspectos psicológicos envolvendo o lazer (SCHWARTZ, 2004). Estes conflitos ocorrem em locais públicos, onde existem órgãos de segurança para tentarem evitar os mesmos. Estes elementos reforçam a satisfação na transgressão à lei por parte dos envolvidos.

Pimenta (1997, p. 73) ao comparar a violência nos estádios brasileiros com os conflitos ocorridos nos países da América Latina, destaca países como Colômbia, Argentina e Uruguai, como aqueles onde a violência em torno do futebol também é frequente. Nestes casos, para esses conflitos, se formariam "[...] verdadeiros grupos de guerrilha urbana [...]", objetivando a busca do prazer proporcionado pela violência.

Dunning (1992, p. 330) estabeleceu uma classificação em relação às diversas formas de violência apresentadas no campo esportivo:

1) Se a violência é real ou simbólica, isto é, se apresenta a forma de uma agressão física directa ou envolve simplesmente atitudes verbais e/ou atitudes não verbais;

2) Se a violência apresenta a forma de um "jogo" ou "simulação", ou se ela é "séria" ou "real". Esta dimensão pode também ser apreendida através da distinção entre violência "ritual" ou "não ritual";

3) Se uma arma ou armas são utilizadas ou não;

4) No caso de armas serem utilizadas, se os atacantes chegam a estabelecer contacto directo;

5) Se a violência é intencional ou a conseqüência acidental de uma sequência de ações que, no inicio, não tinham a intenção de ser violenta;

6) Se se considerar a violência iniciada sem provocação ou como sendo uma resposta, sem retaliação a um acto intencionalmente violento, ou sem a intenção de o ser;

7) Se a violência é legítima no sentido de estar de acordo com as regras, normas e valores socialmente prescritos ou se não é normativa ou ilegítima no sentido de envolver uma infracção dos padrões sociais aceites;

8) Se a violência toma uma forma "racional" ou "afectiva", isto é, se é escolhida de modo racional como um meio de assegurar a realização de um objectivo dado, ou subordinada a "um fim em si mesmo" emocionalmente satisfatório e agradável. Outra forma de conceptualizar esta diferença seria distinguir entre violência nas formas "instrumentais" e "expressivas".

Antes da análise das categorias propostas pelo autor, deve-se compreender um conceitochave elaborado em seu estudo. $\mathrm{O}$ autor relata a busca da excitação agradável, presente nas atividades do contexto do lazer. Assim, as pessoas procuram determinada atividade, em busca do prazer que a mesma pode proporcionar.

Apropriando-se deste conceito, 0 autor entrevistou um hooligan, o qual disse ter tanto prazer por lutas, assim como, por fugir da polícia, que este prazer proporcionado pela violência pode ser comparado ao prazer sexual. Para este hooligan, a briga faz parte do contexto de ir assistir a um jogo de futebol. Neste exemplo, a assistência à partidas de futebol, aliada a práticas desviantes no lazer, proporcionam a excitação agradável, ou seja, o prazer ocorre por meio da violência, o que os estudos de Pimenta (1997) corroboram.

Considerando os itens elaborados por Dunning e anteriormente expostos, 0 entrevistado apresenta violência real, intencional, transgressora da lei, além de ser agradável para ele, proporcionando a vivência do prazer. Esta entrevista evidencia efetivamente uma prática considerada no âmbito do lazer desviante, por parte do entrevistado. Assim sendo, as torcidas organizadas, assim como os hooligans, se apropriam do comportamento designado no 
âmbito do lazer desviante em suas práticas urbanas. A entrevista aponta também para a constatação de que esta problemática da violência esportiva não está centrada apenas na sociedade brasileira, mas que perpassa outras culturas ao redor do mundo.

Contudo, como compreender este prazer proporcionado pela violência. Quais seriam suas razões e motivações? Dunning (1992) aponta que os estudos acadêmicos somente poderiam responder a esta questão, se fossem realizados envolvendo diversas áreas do conhecimento. $\mathrm{Na}$ opinião do autor, existem causas sociais, fisiológicas e psicológicas, que somente uma ciência não é capaz de contemplar.

Em meio a este fenômeno de violência entre as torcidas, se as motivações para o prazer decorrente da violência permanecem obscuras, já as conseqüências dos atos violentos, por sua vez, são bem evidentes e este artigo pretendeu discutir algumas destas conseqüências, com base na literatura especializada sobre o assunto.

\section{Método}

Este estudo qualitativo, de natureza bibliográfica, contou com a pesquisa de informações em obras de referência, compostas por livros e teses, além da consulta a bases de dados, com os descritores: lazer, torcidas organizadas, agressividade e violência. A coleta foi realizada entre 21 de fevereiro de 2011 e 4 de março de 2011.

\section{Resultados e Discussão}

Primeiramente, cabe salientar, que é complexa a correlação entre os fatores que aqui serão apresentados, não sendo possível determinar exatamente até onde um fator contribui ou não para as manifestações violentas. Os resultados advindos dos estudos pesquisados indicam que, independentemente da gênese do comportamento violento e de suas causas, a mudança no comportamento individual quando em presença de um grupo é um fator importante em relação à violência futebolística, por conseguinte, possui ressonâncias no tempo destinado ao lazer.

A mudança do comportamento seria composta por dois principais motivos: a reunião de muitas pessoas e a comunhão de regras e valores das mesmas. Para melhor compreensão deste aspecto recorre-se ao âmbito da Psicologia do Esporte, em que Machado (1997) aponta que fatores econômicos, políticos ou socioculturais podem influenciar o comportamento e a atitude dos torcedores.
Desta forma, um primeiro fator constituinte da mudança do comportamento é decorrente da reunião de indivíduos, tal como ocorre nas torcidas. Toledo (1996, p. 86) aponta que: "[...] este comportamento de massa tende a alterar certos valores, expectativas, sentimentos e o sentido das ações individuais". Desta forma, tal ambiente grupal pode representar uma válvula de escape para a manifestação de condutas agressivas.

Pimenta (1997, p. 99) aponta as torcidas como um "[...] instrumento que reproduz as relações desenvolvidas na sociedade, num viés contrário, refletindo na formação de novos tipos de comportamentos, fundamentos no uso da força física". Esta reunião de indivíduos pode estimular a expressão de comportamentos socialmente reprimidos.

Um destes comportamentos reprimidos é a violência, pois, devido ao processo civilizatório, inicia-se um repúdio a manifestações violentas. Desta forma, a tendência deveria ser a de diminuição de ocorrência destes tipos de manifestações agressivas. Neste processo, entendeu-se que, caso o comportamento violento aparecesse, caberia ao Estado reprimi-lo. Esta exclusividade da repressão, por parte do Estado, ocorreu devido ao monopólio do mesmo, no uso da força contra manifestações violentas (DUNNING, 1992). Afinal, nem sempre as condutas em grandes grupos são habituais do

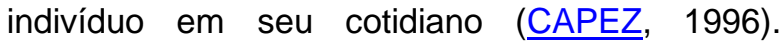
Pimenta (1997, p. 95), a esse respeito, aborda que os torcedores também possuem outros papéis sociais, no entanto, quando estão presentes neste grupo das torcidas organizadas, assumem a identidade coletiva de "[...] intimidação, masculinidade, truculência, força física e tensões emocionais."

Talvez, a necessidade de serem diferenciados dos torcedores comuns, possa contribuir também nesta mudança de comportamento. Esta necessidade fica evidente na escolha de seus símbolos, bem como, nas próprias atitudes. Um exemplo simples é que os torcedores organizados assistem às partidas em pé, sentando-se somente nos intervalos. Esta postura é exatamente oposta à dos torcedores comuns, que assistem ao jogo, sentados, levantando-se, somente, durante os intervalos.

Dentro desta lógica, os torcedores organizados necessitam de distância real e simbólica dos torcedores comuns. Querem ser reconhecidos como únicos (TOLEDO, 1996). Esta postura diferenciada adotada pelas torcidas, possui relação com 0 segundo fator contribuinte na 
mudança de comportamento, a comunhão de regras e valores destes grupos.

Inicialmente, para pertencer ao grupo o indivíduo deve compactuar com suas regras. As regras das torcidas versam sobre diversos elementos, todavia, neste momento, somente será destacado 0 uso da vestimenta, principalmente a camiseta.

Usar a camiseta de uma torcida organizada "[...] reforça o compromisso com o grupo." (TOLEDO, p. 57). Com isso, pode-se dizer também que a camiseta é um símbolo de reforço do sentimento de pertencimento a esse grupo. $O$ indivíduo, ao utilizá-la, deve assumir determinadas posturas, assim como relata Toledo (1996, p. 57), ao se referir que a camisa "[...] relaciona-se a uma certa conduta e estética; assumir-se enquanto um membro de uma Torcida Organizada é, sobretudo, assumir seus símbolos e marcas.".

Uma destas posturas também pode ser observada quando existe a mudança na rota, ou seja, no trajeto do individuo até o estádio. A partir disto, os torcedores organizados parecem possuir certa obrigação de realizarem em conjunto o trajeto: casa - sede da torcida - estádio. Com isto, ocorre uma mudança geográfica da distância entre casa e estádio, modificando-se a área a ser percorrida por um torcedor. Subjacente a esta mudança, ocorre a valorização da sede para estes torcedores. Tais elementos possuem relação com a comunhão dos valores das torcidas e o significado de pertencimento ao grupo.

Outra postura que normalmente é assumida é a de rivalidade, pois o pertencimento ao grupo reforça identidades, solidariedade e oposições, conforme salienta Toledo (1996). A rivalidade, muitas vezes, pode gerar a violência de uma forma extrema, sendo assim, há necessidade de separação espacial, o que já se tornou uma praxe nos estádios.

Esta separação ocorre, não somente no campo de jogo entre os times e nas arquibancadas entre as torcidas, mas chega a ultrapassar os limites do jogo, delineando, até mesmo o percurso para a chegada ao estádio. (TOLEDO, 1996). Toledo (1996, p. 76) denominou este fato como "[...] apropriação privada do espaço público.". Este fato ocorre principalmente nas grandes cidades, quando, nos dias de grandes jogos, devem ser conhecidos os trajetos, a fim de evitar os confrontos, pois existe determinada rota a ser seguida para tal.

Muitas vezes, o percurso mais rápido ou mais simples entre a residência e o estádio não pode ser utilizado, devido às ruas possuírem alto número de torcedores de outra equipe, ou seja, se estaria cruzando uma área teoricamente pertencente à outra torcida, invadindo um território inimigo. Entretanto, existem pessoas que cruzam estes limites, tanto de forma equivocada, como de modo deliberado e nestes encontros entre torcedores a tensão se faz evidente.

O encontro com um torcedor organizado, de qualquer torcida gera reações diferentes daquelas ao se encontrar um torcedor comum. Tais emoções, geralmente, não são positivas, dentre elas estão medo e ódio, por exemplo. Para Toledo (1996), entretanto, esta divisão espacial acaba exacerbando ainda mais as rivalidades.

Em decorrência da comunhão de valores e regras, que muitas vezes perpassam ideologias bélicas (MURAD, 2007) ou estão pautadas na auto-afirmação por meio da violência (PIMENTA, 1997), ao vestir a camiseta da torcida organizada, delimita-se o espaço do indivíduo, no espaço da própria cidade. Já aparece aqui uma primeira ressonância da violência das torcidas organizadas nas atividades do contexto do lazer, evidenciada por meio da apropriação privada do espaço publico. Muitas pessoas acabam sendo privadas de seu direito como cidadão, em decorrência das diversas manifestações violentas que ocorrem durante os dias de jogos.

Somado à comunhão de regras, existe ainda a alta subordinação dos componentes da torcida em relação aos seus diretores, o que colabora com o estabelecimento destes comportamentos. Toledo (1996) evidencia essa subordinação ao descrever, durante uma viagem feita ao Rio de Janeiro para assistir a uma partida contra o Vasco, que se pode perceber os componentes acatando de forma significativa as ordens de um diretor de torcida.

O contexto sociohistórico de criação das torcidas organizadas também possui relevância na expressão violenta e agressiva dos torcedores. Assim, desde o início, se tornam nítidas as relações da história da organização das torcidas com o cenário atual, sobre algumas das regras e valores deste grupo específico.

O início das manifestações de torcidas organizadas se deu na época correspondente à ditadura militar brasileira, período de violência, perseguições e repressão a manifestações sociais. As torcidas organizadas surgem para reivindicar aspectos do clube e exercer participação política, que os torcedores comuns não conseguiam (TOLEDO, 1996). 
Os chefes das torcidas possuíam grande prestígio no ambiente das torcidas e iniciaram a reivindicação de um espaço não obtido até aquele momento. Este espaço que as T.O. conseguiram dentro dos clubes foi decisivo e revolucionário em determinados momentos, principalmente nos desfavoráveis, culminando, inclusive, na demissão de jogadores e treinadores. Porém, esta participação política que a torcida buscava também no âmbito do Estado, Ihe foi negada, tendo em vista os ditames políticos da época, revigorando ainda mais a efervescência interna como grupo social.

Mediante essa era de muita repressão e censura, a falta de participação política pode ter migrado da esfera social, para a esfera esportiva. Assim, as torcidas nasceram com um caráter revolucionário. Este fato pode ser evidenciado em diversas bandeiras de torcidas com alusões a figuras revolucionárias, com Che Guevara, por exemplo.

Todavia, apesar deste caráter revolucionário, estes grupos mantiveram e reproduziram as mesmas relações de poder existentes na esfera da sociedade, uma vez que somente um grupo pequeno controla a torcida organizada, assim como no governo. Este grupo seleto é de difícil acesso e possui goza de grande respeito por parte dos demais integrantes (PIMENTA, 1997).

A partir deste argumento de manutenção da ordem social, Pimenta (1997) discorda de que as torcidas estejam substituindo a família, Estado e outras instituições sociais, pois a separação e diferenciação social são mantidas neste grupo também. Toledo (1996), ao descrever uma de suas viagens feitas a São Januário, verificou alguns destes elementos que evidenciavam essa separação apontada anteriormente por Pimenta, dentro da torcida. Nesta viagem, Toledo salienta que cerca de 400 pessoas saíram de São Paulo e foram divididas conforme suas características e/ou "status" na torcida.

Desta maneira, percebe-se a criação de grupos menores, dentro da própria torcida, reproduzindo os padrões sociais, que são fundamentados nas diferenças. $O$ alto escalão daquele grupo social, a diretoria, viajou no mesmo ônibus. Em meio àquele ambiente, devido ao prestígio conquistado, os componentes da torcida se dirigiam à diretoria respeitosamente, com expressões como: "ô meu presidente", conforme relatou Toledo (1996).

A criação de pequenos grupos dentro da torcida leva à aglutinação de sujeitos semelhantes de diversas formas. Esta divisão, como relata Toledo (1996), pode ser um fator estimulador de violência, pois os indivíduos mais agressivos tenderiam a se agrupar, tendendo a fortalecer a expressão do comportamento violento.

Os resultados deste estudo indicam a composição das torcidas, como um fator que pode gerar manifestações violentas. Em torno deste fator, a variedade de pessoas, com diferentes idades e de diversas classes sociais chama a atenção. As torcidas, muitas delas, são formadas por jovens de faixa etária entre 15 e 17 anos, em sua maioria. Estes jovens necessitam de afirmação social, podendo esta acontecer por meio da violência, no ambiente das torcidas organizadas. Em relação à classe social, a predominância observada é entre as classes $\mathrm{B} e$ C (TOLEDO, 1996).

Nos debates vinculados na mídia, conforme salienta Pimenta (1997), a formação das torcidas com muitos jovens é apontada como capaz de ocasionar, com maior freqüência, episódios violentos. Apesar de os jovens não serem, exclusivamente, os únicos responsáveis pela violência, é inegável a participação destes em diversos episódios. Isto fica evidente, nas mortes noticiadas envolvendo menores de 18 anos (PIMENTA, 1997). Estes fatos constantemente chamam a atenção em relação ao fenômeno da violência futebolística.

A concepção de que os jovens contribuem com a violência é decorrente da necessidade de afirmação social que esta fase do desenvolvimento geralmente apresenta. $O$ universo das torcidas organizadas, que possui elementos como: coesão grupal, comunhão de regras e valores, lealdade, companheirismo, pode ser um atrativo para a adesão destes jovens às torcidas. Novamente, é importante ressaltar os diversos papéis sociais exercidos pelos indivíduos, além do papel de torcedor. Além dos jovens, há grande diversidade de pessoas que compõem as torcidas organizadas, sendo elas de diferentes idades, crenças e classes sociais. É constantemente veiculada pela mídia que esta composição das torcidas com muitos jovens proporcionaria um ambiente para escamotear marginais, desocupados, vândalos, pessoas sem família e vagabundos.

Reis (2011), no I Seminário de Hooliganismo, demonstra os seguintes dados sobre as torcidas organizadas. Tendo como base a composição familiar, 87, 5\% moram com família original. Já em relação à escolaridade, 32\% possuem Ensino Médio completo, 31,5\% possuem Ensino Médio Incompleto, 8\% possuem Ensino Superior completo e $10,5 \%$ pós-graduação. PIMENTA (1997) contribuiu com mais dados para esta 
discussão, em estudo anterior, evidenciando que, em relação à atividade profissional dos torcedores tem-se que:

Tabela 1- Atividade profissional dos torcedores (PIMENTA, 1997).

\begin{tabular}{lc}
\hline \multicolumn{1}{c}{ Tipo de trabalho } & $\%$ \\
\hline Assalariados e atividade profissional & 73,8 \\
Desempregado ou subsidiado & 25,0 \\
Não responderam & 1,2 \\
\hline
\end{tabular}

Em relação à faixa de $25 \%$ apontados como desempregados ou subsidiados, cabe uma ressalva. Nesta faixa estariam os adolescentes e jovens, os quais participam das torcidas organizadas. O mesmo autor apresenta os dados com relação à escolaridade:

Tabela 2- Grau de escolaridade dos torcedores (PIMENTA, 1997).

\begin{tabular}{lc}
\hline \multicolumn{1}{c}{ Grau Escolar } & $\%$ \\
\hline Assalariados e atividade profissional & 73,8 \\
Desempregado ou subsidiado & 25,0 \\
Não responderam & 1,2 \\
\hline
\end{tabular}

Tabela 3- Tipo de escola dos torcedores (PIMENTA, 1997).

\begin{tabular}{lc}
\hline \multicolumn{1}{c}{ Tipo de escola } & $\%$ \\
\hline Pública & 65,8 \\
Privada & 34,2 \\
\hline
\end{tabular}

Desta forma, ambos os estudos apresentados contrariam o mito de que as torcidas abrigam indivíduos à margem da sociedade e vagabundos. No entanto, restam ainda alguns desafios, entre eles, como compreender a grande atração dos jovens para este fenômeno?

Reis (2005) aponta a crise moral como um fator contribuinte para a grande quantidade de jovens nas torcidas, pois os jovens conseguiriam aceitação e sucesso que não obtiveram na família e no trabalho, escola, etc. Pimenta (1997) aponta o esvaziamento do Estado no tecido social, gerando a formação de novos indivíduos, com novos padrões de comportamento. Sendo assim, os novos indivíduos possuem um novo estilo de vida e novas características, sendo uma delas a violência.

Já em relação ao segundo fator, a classe social, para Dunning (1992) adolescentes e jovens das classes trabalhadoras mais rudes parecem ter maior participação nos episódios de comportamento hooligan no contexto inglês. Com relação às torcidas organizadas, Pimenta (1997) destaca a diversidade de pessoas presente dentro de uma torcida. Desta forma, não é possível classificar a origem da violência conforme a classe social.

Reis (2005) relata a dificuldade de se abordar esta temática, pela falta de estudos com dados consistentes e a falta de informação nos registros das torcidas organizadas. A autora destaca somente os estudos de Cardia (1996), Capez (1996) e Telles (1996) como estudos abordando tal temática.

Se a composição das torcidas é capaz de estimular ou coibir a violência, a partir de agora serão estabelecidas algumas relações com a violência futebolística propriamente dita. Os resultados da presente pesquisa apontam que a violência e a agressividade fazem parte do contexto de vida dos torcedores, ou seja, são elementos que permeiam suas vidas. Estas podem possuir diversas motivações e serem demonstradas de diferentes formas, como por exemplo: na mídia, pelo número exacerbado de desenhos, filmes e noticiários que contenham violência; nas relações de poder, por meio da conduta autoritária de diversas instituições; na linguagem, entre outras.

Reis (2006, p. 14) explicita que o futebol contém uma carga de violência na própria dinâmica do jogo. A origem do futebol possui "[...] valores masculinidade, valores exacerbados de virilidade, força e sobrepujança [...] ". O futebol foi um ambiente fértil para o surgimento de grupos masculinos que fazem normas de masculinidade e a luta é uma destas normas (DUNNING 1992). Aqui, desponta a relação da violência intrínseca ao futebol com a comunhão de regras das torcidas.

Todavia, cabe salientar que a violência não é somente proveniente do próprio futebol. Há relação da violência com fatores sociais, bem como, há relação com a própria formação moral do indivíduo (REIS, 2006). Desta forma, a violência faz parte do próprio contexto do futebol, assim como, do contexto social, podendo ter graves e sérias consequências.

Em relação a este contexto social, as torcidas surgem nos ambientes urbanos, como conseqüências, por exemplo, de uma mudança do campo para a cidade, do estabelecimento e da superpopulação de indivíduos em bairros periféricos, ou seja, como resultado da crescente e desenfreada urbanização (PIMENTA, 1997). A violência, como parte deste contexto, pode ser expressa de diversas formas e pode ter causas variadas.

No que tange à violência das T.O., Reis (2006) e Toledo (1996) apresentam diversos fatores que contribuem para tal. A centralidade do futebol na vida do torcedor, principalmente do organizado, que chega a dedicar-se exclusivamente à torcida, como retrata Toledo (1996) na excursão de 
corintianos à Bahia, para ver um jogo de futebol, parece ser uma delas.

A centralidade do futebol gera um sentimento coletivo em torno do clube. Este sentimento pode fazer com que o torcedor não estabeleça claramente os limites entre a sua identidade e a do outro (REIS, 2006). Por este motivo, existem casos de torcedores, que passam a interferir em questões pessoais de jogadores, causando situações desagradáveis como perseguições e cobranças excessivas. Aqui fica evidente mais uma conseqüência da violência das torcidas no tempo destinado ao lazer. Desta vez, os jogadores de futebol são as vítimas da violência. Tais condutas são características de torcedores fanáticos.

O fanatismo possui relação com a falta de oportunidades em relação à prática do futebol. $\mathrm{A}$ falta da vivência crítica do futebol pode gerar concepção reduzida sobre o fenômeno do esporte. Assim, o individuo não seria capaz de aceitar claramente os diversos interesses que giram em torno do futebol, como por exemplo, a manipulação de resultados (PIMENTA, 1997).

O fanatismo, por sua vez, pode gerar agressividade, que é manifesta na relação do torcedor com seus rivais. Assim, a rivalidade é expressa nas ofensas contra os outros torcedores, tema que será abordado adiante, nos cantos das torcidas.

Os próprios resultados da equipe podem desencadear a violência, por exemplo, quando se tem um longo período sem títulos. Outros fatores que podem desencadear a violência são as declarações de personagens envolvidos, sendo eles: dirigentes, jogadores, treinadores, entre outros, o clima de guerra criado pela mídia, a ação da polícia, consumo de bebidas e a falta de infra-estrutura (PIMENTA, 1997).

As declarações dos personagens do jogo e 0 clima de guerra são informações veiculadas por repetidas vezes pela mídia. Diversos estudos (PIMENTA, 1997; REIS, 2006; MURAD, 2007) consideram que a violência pode ser estimulada pela mídia. Sintetizando estas informações Murad (2007) critica a mídia devido ao sensacionalismo exacerbado, por generalizar os torcedores como violentos $e$, inclusive, por pensar somente na audiência em detrimento da verdade.

A partir destas críticas o olhar é dirigido para se analisar os meios de comunicação, especialmente, televisão e rádio. Em ambos existem programas exclusivos de futebol. Cabe ressaltar, o grande acesso da população, principalmente a urbana, aos meios de comunicação de massa, sendo esta a mesma população que possui acesso às torcidas organizadas como atividade do âmbito do lazer. Nestes programas, geralmente, há discussão das partidas, além da repetição constante de lances polêmicos, conforme constata Murad (2007). Tais medidas visam atrair audiência significativa, pois, conforme salienta Reis (2005) o futebol, como fruto do sistema capitalista, deve ser rentável, um produto a ser consumido.

Desta forma, Reis (2005) corrobora o pensamento de Betti (1997), em relação ao esporte espetáculo, em que o futebol é considerado como uma mercadoria que deve ser consumida por toda a sociedade. A autora ainda retrata a irresponsabilidade com que alguns dos envolvidos com a mídia esportiva tratam a questão da violência, o que também é evidenciado por Murad (2007). Estes programas esportivos, agindo de maneira sensacionalista, são capazes de modificar opiniões facilmente. $\mathrm{Na}$ opinião dos próprios torcedores organizados, a mídia é algo que perseguiria as torcidas (PIMENTA, 1997).

A capacidade da mídia em modificar opiniões conta, algumas vezes, com estratégias como a generalização simplista e disseminação do terror, por meio de opiniões e campanhas contendo slogans como: "Não vá aos estádios". Afinal, na opinião de muitos cronistas esportivos os estádios estão repletos de vagabundos. Nestas campanhas transparece a capacidade da mídia em gerar violência, utilizando como argumento a composição denegrida destas torcidas.

Porém, os dados aqui apresentados ajudam a desvendar alguns mitos em torno do assunto, com o intuito de apontar outra situação. Da mesma forma que a mídia prejudica a imagem das torcidas, também a enaltece, estabelecendo, assim como apontam Reis (1998) e Silva (2001), uma posição ambígua em relação a elas. Nos veículos de comunicação de massa, as torcidas são criminalizadas e tomadas como as responsáveis pelos episódios de violência nos estádios, porém, quando se fala da festa e do elemento estético das arquibancadas, se utilizam imagens destas mesmas torcidas.

Esta relação ambígua, ainda perpassa os benefícios que a mídia proporciona ao futebol e, por conseguinte, às torcidas. Como já foi apontado na introdução, a mídia contribui para a expansão e profissionalização do futebol.

Por fim, pode-se dizer que o papel ambíguo da mídia pode interferir negativamente, inclusive nas atividades do contexto do lazer, por meio das campanhas e da perseguição das torcidas. 
Entretanto, pode também estimular a presença aos estádios, com as imagens veiculadas na televisão.

A ação da polícia, conforme já citado, é outro fator que pode gerar violência. Reis (2006) aponta que, mediante a violência por parte dos órgãos públicos, os torcedores respondem também com violência, seja física ou simbólica, expressandose, principalmente, por meio de músicas. Pimenta (1997, p.126) ao descrever a ação dos policiais relata que a intervenção "[...] se resume em socos, chutes, cassetetes entre outros [...]", ou seja, com o uso da força, força restrita ao Estado, como descrito por Dunning (1992). Desta forma, o papel destas autoridades pode diminuir ou aumentar a violência (TOLEDO, 1996; PIMENTA, 1997; REIS, 2006), sendo necessário maior empenho de gestores de políticas públicas em ampliar o apoio aos estudos que promovam novas estratégias para minimizar esse quadro.

Em decorrência desta relação conturbada entre T.O. e policiais, as torcidas, por vezes, demonstram algum tipo de antipatia para com a polícia. Os torcedores respondem de maneira violenta à intervenção da polícia, não somente violência física, mas também a verbal, configurando-se como uma violência por meio da linguagem.

Tomando-se por foco a linguagem, percebe-se que diversas letras de músicas cantadas pelas torcidas estimulam a violência e possuem alta conotação e denotação violenta e/ou agressiva (REIS, 1998). Diversos estudos (DUNNING, 1992; TOLEDO, 1996; PIMENTA, 1997; REIS, 1998) demonstram diferentes canções que são entoadas pelas torcidas, nos estádios ou fora deles, contendo um caráter agressivo em suas letras.

Estas músicas servem também como ameaça, além de demonstrarem vanglórias por vitórias passadas contra os rivais. Constituídas de palavras extremamente violentas como: luta, morte, pontapé, rendição, as músicas podem possuir um viés sexual, pois, destacam um papel sexual submisso e com conotação homossexual para ampliar a chacota, sendo estas características dirigidas para os rivais (DUNNING, 1992).

Reis (1998, p. 104) observou a predominância de agressões simbólicas no ambiente do estádio, gestos, xingamentos e cantos em determinados momentos. A predominância deste tipo de violência acontece por esta ser "[...] legitima, está de acordo com regras normas e valores socialmente prescritos e aceitos.". No estádio de futebol existiria a instauração de uma ordem diferente da cotidiana, onde, por exemplo, falar palavrões é aceitável e desculpável (TOLEDO, 1996; REIS, 1998).

Com isso, a violência simbólica expressa nas manifestações da torcida, principalmente nos cantos, variam de acordo com o momento do jogo. No início das partidas, estes cantos visam exaltar a equipe. No intervalo, variam de acordo com os acontecimentos da primeira etapa, podendo, até, serem direcionadas ofensas, não somente à torcida rival, mas a outros componentes do jogo, como policiais, árbitro, técnicos e jogadores adversários, ou até mesmo, da equipe do torcedor.

As músicas acabam desempenhando uma função de diálogo entre diferentes grupos do estádio. Esta forma de manifestação é bastante recorrente em meio às T.O., entretanto, os torcedores comuns também as utilizam (REIS, 1998). Toledo (1996) classificou os palavrões e cantos em quatro tipos: auto-afirmação, incentivo, intimidadores e de protesto.

Como Dunning (1992) já evidenciou, nota-se que a sexualidade permeia estes cantos. Mediante um ambiente diferenciado do cotidiano, as palavras de baixo calão, acompanham estes gritos. Assim sendo, os palavrões destacam determinadas características, por exemplo, nos gritos de intimidação, as características masculinas de virilidade e truculência são exaltadas. A partir destas características é possível relacionar as músicas com a rivalidade. Toledo (1996) expõe esta problemática ao citar os diversos "apelidos" que as torcidas costumam receber.

O problema central da linguagem como forma de violência é que a alta quantidade de violência simbólica presente nos cantos das torcidas, bem como, nos estádios, pode gerar violência real. A violência real pode ser estimulada pelo consumo de drogas licitas e ilícitas, como, por exemplo, o álcool. Sob o efeito destas substâncias, há maior adesão a comportamentos não comuns, como os violentos ( $\underline{\mathrm{REIS}}, 2005)$.

Desta forma, os resultados desta pesquisa apontam outro fator que contribui para 0 aparecimento de manifestações violentas, referente ao uso de álcool. Dunning (1992) evidencia que o álcool faz com que o individuo perca a inibições, sendo mais difícil distinguir comportamentos desejáveis de indesejáveis.

$\mathrm{Na}$ Inglaterra, a ingestão de bebida alcoólica, é uma das razões mais aceitas para explicar o comportamento hooligan. Contudo, as discussões devem ser aprofundadas, pois nem todos os 
hooligans bebem. Além do mais, esta conduta de ingestão de bebidas alcoólicas prejudicaria 0 hooligan no ato da busca da excitação agradável, mais especificamente para este caso, na luta (DUNNING, 1992).

A violência pode ser gerada também por questões ligadas à organização esportiva, assim como, a falta de medidas punitivas. Reis (1998; 2006), em seus estudos, evidenciou diversos problemas na estrutura atual do futebol nacional, que condicionariam à violência. Inicialmente, destaca-se a existência de dirigentes, principalmente dos grandes clubes, que não se preocupam com o time, sendo estes, um dos grandes culpados pela atual situação do futebol brasileiro. Tais dirigentes podem ser os mesmos responsáveis pela pouca organização esportiva.

Estes fatores, não são evidentes nos dias de jogos para os torcedores, entretanto, inúmeras outras condições são bem visíveis e constantes nos estádios brasileiros. Primeiramente, o sistema de venda de ingressos contendo desorganização, filas gigantescas, ação de cambistas e falsificações podem ser agravantes para incentivar condutas de revolta e violência. A falta de condições de acesso aos estádios, incluindo falta de transporte público e estacionamentos, são fatores primordiais, sendo bastante considerados pela Federação Internacional de Futebol (FIFA) na realização de uma Copa do Mundo ( $\underline{\text { REIS }}$, 2006).

Outra condição perceptível para o torcedor são as questões físicas do estádio. A ausência de assentos em todos os setores, condições de limpeza e higiene inadequadas, principalmente em banheiros, pouca variedade na alimentação, falta de câmeras de segurança, são apenas alguns dos problemas dos estádios brasileiros. A utilização de câmeras de segurança é importante e ajudou a responsabilizar os participantes da torcida "Império Verde" em 2009, por suas ações, quando invadiram o campo e agrediram árbitro, policiais e jogadores, após o término da partida entre Coritiba e Fluminense, que culminou no rebaixamento da equipe curitibana.

O não cumprimento total do Estatuto do Torcedor (BRASIL, 2003), também demonstra o descaso e desrespeito com o torcedor. Esse estatuto foi elaborado em forma de Lei $n$. $10.671 / 03$, e visa defender o torcedor como um consumidor. Desta forma, a organização do futebol deve prezar pelo respeito e pela transparência, inclusive, com relação ao torcedor. Este problema toma proporções ainda mais preocupantes, visto que o Brasil será a próxima sede da Copa do Mundo de futebol e as mudanças relativas a adequações necessárias ainda não foram efetuadas nos estádios brasileiros.

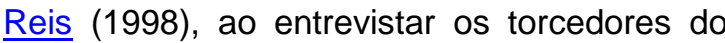
Palmeiras, evidencia a falta de instalações adequadas, as quais, por sua vez, inibiam a participação feminina nos estádios. Na opinião da autora, a presença de mulheres poderia também contribuir para a diminuição da violência. Os entrevistados de sua pesquisa ressaltaram também que esta desorganização representa a própria violência.

Esta é outra ressonância da violência no âmbito do lazer. As mulheres, em meio ao ambiente violento, procuram se esquivar de comparecer nos estádios ou, não raro, são excluídas do ambiente futebolístico. A violência promove, então, ressonâncias negativas no que se refere a estas atividades do contexto do lazer das mulheres.

A falta de medidas punitivas pode também pode reforçar a violência, pois os praticantes de agressão se sentem mais à vontade para cometerem delitos. A proibição da entrada de sujeitos com histórico violento, fazendo com que os mesmos compareçam às delegacias nos horários dos jogos, seria uma medida preventiva, a fim de impedir a participação deste sujeito no estádio novamente. Esta medida preventiva, dentre outras, seria um contribuinte importante para acabar com a impunidade ainda vigente (REIS, 2006).

\section{Considerações Finais}

No processo de desenvolvimento do futebol, em meio aos grandes centros urbanos, este passa a possuir muitos adeptos e ser uma atividade de grande relevância social. Concomitantemente a isto, diversos conflitos são constituintes do espaço urbano de criação das grandes cidades. Este processo gerou a formação de novos indivíduos, que se expressam pela negação do outro e pelo confronto entre grupos. A noção do coletivo é praticamente nula. Neste contexto já emocionalmente exacerbado, surge o torcedor organizado, que se sente parte do jogo (PIMENTA, 1997), um jogo que, nem sempre, traz consigo as características de uma atividade lúdica por si só, mas, evidencia-se, inclusive, como um campo de disputas políticas, mercadológicas e de afirmação de status.

Estas evidências ressaltam a violência e a agressividade envolvidas, tanto na prática como na assistência a esses jogos como torcedor. Estes aspectos, conforme a literatura pesquisada, podem acabar delimitando o tempo, o espaço e 
as atividades do contexto do lazer, especialmente para as mulheres. Em relação ao tempo e espaço, esses elementos podem provocar a mudança de roteiros e hábitos, bem como, o esvaziamento dos estádios. Já com referência às atividades, estas podem interferir ampliando a perspectiva de exclusão de determinado público nos estádios de futebol, especialmente mulheres e crianças, como vítimas mais freqüentes. Incluem-se nesta categoria também os idosos, que já não são tão assíduos freqüentadores dos estádios, devido à falta de estrutura para a recepção e acomodação, bem como, pelo fato de também acabarem sendo vítimas da violência.

Tanto a violência como a agressividade podem acarretar graves conseqüências físicas e/ou psicológicas aos envolvidos, tendo, inclusive, a possibilidade de gerar vítimas fatais. Uma família que perdeu um parente em um jogo de futebol, certamente reconsiderará seus conceitos acerca desta atividade no âmbito do lazer, assim como, as diversas pessoas que sofreram agressões ou até perderam a vida, enquanto buscavam a excitação agradável, por meio do futebol.

Reis (2006) aponta que a violência no futebol possui razões sociais e que estas vão além da dependência da existência de Torcidas Organizadas, principalmente, quando 0 argumento utilizado, de forma subjacente, é a classe socioeconômica. As péssimas condições dos estádios, mídia, má organização esportiva e a ação policial também contribuem para a configuração da violência no futebol.

Torna-se importante proceder-se a análises aprofundadas dessas inúmeras variáveis que aparecem ao se analisar o esvaziamento dos estádios, não somente pelo viés da violência, mas também, por outros fatores que contribuem para isto, como por exemplo, o preço envolvido no processo de participação e assistência a uma partida, a precariedade do transporte, a descabida distribuição de ingressos. Soma-se a estes agravantes, inclusive, o baixo nível técnico e de desempenho das equipes. Todos esses fatores interferem sensivelmente na configuração do lazer contemporâneo.

O lazer, na atual sociedade é a única esfera pública em que as decisões podem ser tomadas buscando, antes de tudo, a satisfação pessoal (DUNNING, 1992). No entanto, nas atuais condições, como buscar esta satisfação em meio a um cenário de violência extrema? Esta violência pode interferir não somente no lazer, mas também, em outras esferas da vida humana, como o trabalho, nas depredações que ocorrem nos trens, metros e ônibus coletivos das cidades, tornando-se um problema a ser gerido, tanto política quanto economicamente.

Em meio a estes dados preocupantes está a confirmação do país como cidade sede de megaeventos, entre eles, a Copa do Mundo de futebol. Para que esta tarefa ocorra de forma razoável em termos de segurança, infraestrutura e público, tornam-se prementes que novas políticas públicas de esporte e lazer sejam configuradas no país, contemplando, inclusive, a educação para o lazer, no sentido de apreender o lazer como um espaço para ressignificação e mudança de atitudes e crenças, visando também a formação de cidadãos aptos para um convívio com qualidade.

Torna-se vital, inclusive, a sistematização de novas políticas públicas específicas para os megaeventos, principalmente pensando-se na Copa de 2014, no sentido de prevenir condutas violentas, uma vez que este evento contará com a presença de torcidas com histórico violento, como Ultras, Barra Bravas e Hinchas, além das torcidas organizadas. Sugere-se, também, que novos estudos sejam efetivados em âmbito acadêmico, para que se consiga ampliar as possibilidades de configuração de novas estratégias, capazes de subsidiar a implementação de políticas públicas eficientes, na perspectiva de contribuir interdisciplinarmente com outras reflexões acerca desta relevante temática.

\section{Referências}

BETTI, M. Violência em campo: dinheiro, mídia e transgressão às regras no futebol espetáculo. ljuí: Ed. UNIJUÍ, 1997.

BRASIL. Lei no 10.671 de 15 de maio de 2003. Dispõe sobre o Estatuto de Defesa do Torcedor e dá outras providências, 2003. Diário Oficial [da] Repúbica Federativa do Brasil, Brasília, DF, 16 maio 2003.

CAPEZ, F. Violência no futebol. In: LERNER, J. (Org.). A violência no esporte. São Paulo:

Secretaria da Justiça e da Defesa da Cidadania/IMESP, 1996. p. 49-52.

CARDIA, N. A violência no futebol e a violência na sociedade. In: SÃO PAULO (Estado). Secretaria de Estado da Justiça e de Defesa da Cidadania. A violência no esporte. São Paulo, 1996.

DA MATTA, R (Org.). Universo do Futebol: esporte e sociedade brasileira. Rio de Janeiro: Pinakotheke, 1982.

DAOLIO, J. (Org.) Futebol, cultura e sociedade. Campinas, SP: Autores Associados, 2005. 
DUNNING, E. A busca da excitação. Lisboa, Difel: 1992.

\section{ESCHER, T. A. REIS, H. H. B; Futebol e} sociedade. Brasília: Liber Livros, 2006.

GOMES, L. C. Lazer, trabalho e educação: relações históricas, questões contemporâneas. Belo Horizonte: Editora UFMG, 2008.

MACHADO, A. A (Org.). Psicologia do esporte: temas emergentes. Jundiaí: Ápice, 1997.

MÁRIO FILHO. O negro no futebol brasileiro. Rio de Janeiro: Civilização Brasileira, 1964.

MURAD, M. A violência e o futebol: dos estudos clássicos aos dias de hoje. Rio de Janeiro: Ed. FGV, 2007.

PIMENTA, C. A. M. Torcidas organizadas de futebol: violência e auto-afirmação, aspectos da construção de novas relações sociais. Taubaté: Vogal, 1997.

REIS, H. H. B. Futebol e sociedade: as manifestações da torcida. 1998. $127 \mathrm{f}$. Tese (Doutorado em Educação Física) - Faculdade de Educação Física, Universidade Estadual de Campinas, Campinas, 1998.

REIS, H. H. B. Espetáculo futebolístico e violência: uma complexa relação. In: DAOLIO, J. (Org.) Futebol, cultura e sociedade. Campinas: Autores Associados, 2005.

REIS, H. H. B. Futebol e violência. Campinas: Armazém do Ipê (Autores Associados), 2006.

REIS, H. H. B. Violência das torcidas Organizadas. In: SIMPÓSIO INTERNACIONAL SOBRE HOOLIGANISMO E COPA DO MUNDO DE 2014, 1., 2011, Campinas. Anais...,

Campinas: Centro de Estudos Avançados, 2011.

ROJEK, C. Deviant leisure: The dark side of freetime activity. In: JACKSON, E.L.; BURTON, T.L. (Org.). Leisure studies: Prospects for the twentyfirst century. Pennsylvania: Venture, 1999. p. 8196.

SCHWARTZ, G. M. Aspectos Psicológicos do Lazer. Licere, Belo Horizonte, v. 7, n. 1, p. 9-21, 2004.

SILVA, S. R. Tua imensa torcida é bem feliz...da relação do torcedor com o clube. 2001. 130 f.Tese (Doutorado em Educação Física). Programa de Pós-Graduação em Educação Física, Faculdade de Educação Física, Universidade Estadual de Campinas, Campinas, 2001.
STEBBINS, R. A casual leisure: a conceptual statement. Leisure Studies, London, v. 16, n. 1, p. 17-25, 1997.

TELLES, V. S. Violência e cidadania. In: SÃO PAULO (Estado). Secretaria de Estado da Justiça e de Defesa da Cidadania. A violência no esporte. São Paulo, 1996.

TOLEDO, L. H. Torcidas organizadas de futebol. Campinas: Autores Associados: Anpocs, 1996.

WILLIAMS, D.J.; WALKER, G.J. Leisure, deviant leisure, and crime: 'Caution: Objects may be closer than they appear'. Leisure/Loisir, Waterloo, v. 30, n. 1, 30, p.193-218, 2006.

Este artigo original foi aprovado na categoria de Tema Livre Premiado no VII Congresso Internacional de Educação Física e Motricidade Humana e XIII Simpósio Paulista de Educação Física, realizado pelo Departamento de Educação Física do Instituto de Biociências da UNESP Câmpus de Rio Claro - SP, Brasil, entre os dias 26 a 29 de maio de 2011.

Endereço:

Marcelo Fadori Soares Palhares

Avenida 24 A, 1515 - Bela Vista

Rio Claro SP Brasil

13506-900

Telefone: (11) 2232-2691

e-mail: marcelofsp@hotmail.com

Recebido em: 20 de setembro de 2011.

Aceito em: 29 de setembro de 2011.

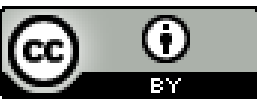

Motriz. Revista de Educação Física. UNESP, Rio Claro, SP, Brasil - elSSN: 1980-6574 - está licenciada sob Creative Commons - Atribuição 3.0 